\title{
Second Opinion
}

\section{Vascular Reconstruction in the Resection of Soft Tissue Sarcomas}

\author{
CHRISTOPHER M. CERALDI, M.D., TO-NAO WANG, M.D., \\ RICHARD J. O'DONNELL, M.D., P. T. MCDONALD, M.D., and \\ STEVEN G. GRANELLI, M.D.
}

ABSTRACT As the specialty of vascular surgery evolves, vascular surgeons may be asked to assist in the management of patients with locally invasive sarcomas that may require vascular resection or reconstruction.

Since July 1, 1996, we have surgically treated 165 patients with sarcoma. Of these, 11 were considered preoperatively to have potential vascular involvement, with 3 ultimately requiring vascular reconstruction or ligation (Table 1 ). An additional patient with a recurrent nonseminomatous germ cell tumor of the pelvis is included because the natural history reflects that of sarcoma, and the surgical management illustrates important technical points regarding en bloc resection and vascular reconstruction. Patient age ranged from 11 to 75 (mean 46). No patients have been lost to follow-up, which has ranged from 1 to 32 months (mean 13.4 months). Four patients had recurrent tumors during follow-up. Those with the smallest tumors and those not requiring vascular reconstruction had the highest rates of cure to date. There was one death in a 32-year-old female with a large thigh leiomyosarcoma who developed pulmonary metastasis 1 year postoperatively.

Four patients required vascular reconstruction. One (patient 2, Table 1) with a metastatic malignant histiocytoma of the groin had persistent disease due to inability to obtain a clear surgical margin. She had refused hip disarticulation. Another (patient 1, Table 1) developed a duodenal recurrence at 1.5 years. $\mathrm{He}$

C.M.C., Assistant Clinical Professor of Surgery, University of CA, Davis-East Bay Department of Surgery (Vascular), Kaiser Medical Center, Oakland, CA; T.N.W., Department of Surgery (Plastic Surgery), Kaiser Medical Center-Oakland, CA; R.O., Chief, Musculoskeletal Oncology Department-Kaiser South San Francisco; P.T.M., Associate Clinical Professor of Surgery, University of CA, Davis-East Bay Department of Surgery (Vascular), Kaiser Medical Center, Oakland, CA; S.G.G., Assistant Clinical Professor of Surgery, University of CA, Davis-East Bay Department of Surgery (Surgical Oncology), Kaiser Medical Center, Oakland, CA.

Copyright (C) 2000 by Thieme Medical Publishers, Inc., 333 Seventh Avenue, New York, NY 10001, USA. Tel. +l(212) 584-4662. 0894-8046,p; 2000,12,2,67,84,ftx,en;pvs00066 


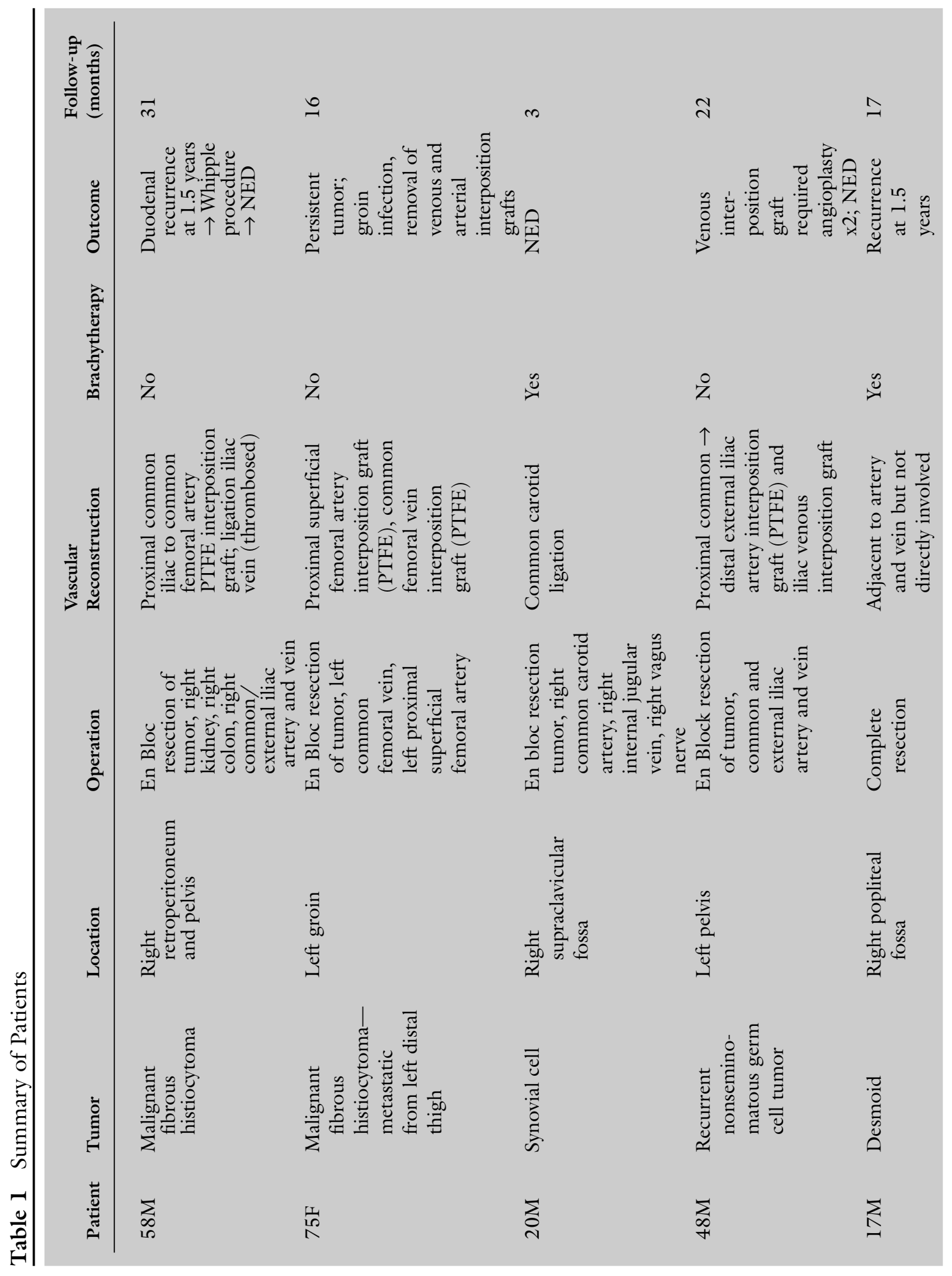




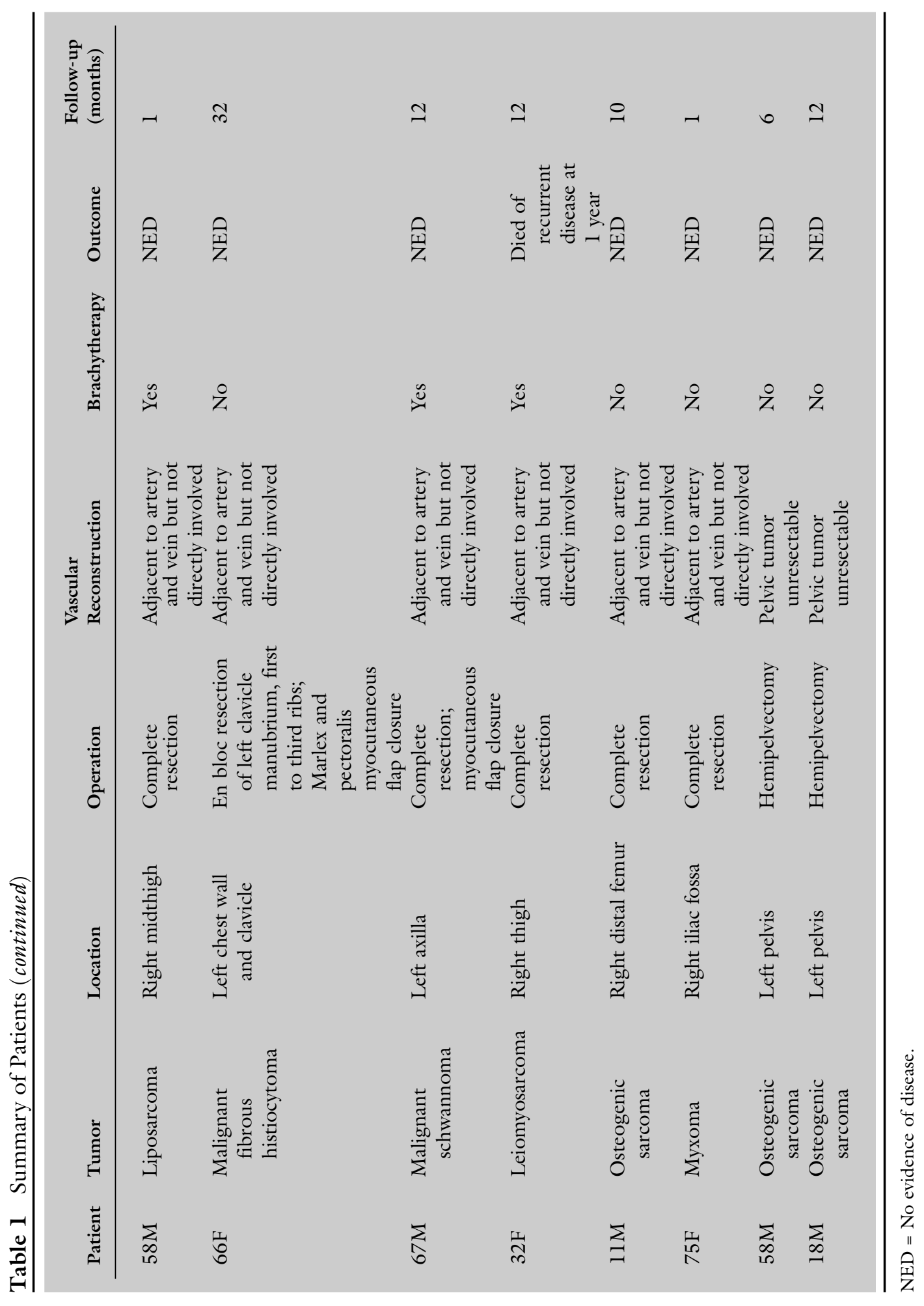


underwent a Whipple resection and is disease-free at 4 months. The remaining two are disease-free at last follow-up.

There were no perioperative deaths. One patient developed a groin wound infection 2 weeks postoperatively that required removal of a proximal superficial femoral artery PTFE interposition graft and common femoral venous interposition graft. Viability of the limb was maintained via profunda collateral, and amputation has not been required. One patient with a prosthetic iliac vein bypass developed a proximal anastomotic stenosis at 3 months, which was successfully treated with balloon angioplasty and stent placement. Repeat angioplasty was required 1 year later, and he subsequently remains asymptomatic at 8 months.

Herein we present the lessons learned in our experience with this unique population of patients. Successful outcome for these cases requires extensive preoperative planning and collaboration among all physicians involved in the patient's care.

Keywords Sarcoma, cancer, multimodel therapy, vascular reconstruction

Historically, malignant tumor invasion or involvement of major vascular structures has precluded surgical resection for cure or even reasonable palliation. For such tumors of the extremities, amputation was recommended even if surgical margins clear of tumor could be obtained. ${ }^{1-3}$ Although such carcinomas remain incurable, recent reports indicate favorable outcomes for soft tissue sarcomas treated by radical surgical resection, with or without adjuvant chemotherapy and radiation therapy. ${ }^{4-7}$ In a large number of these cases it will be necessary to perform extensive dissections of the involved artery and vein for complete tumor exterpation. In approximately $5 \%$ of cases, an integral part of this aggressive approach will require a vascular reconstruction of the involved vein as well as the artery.

\section{GENERAL CONSIDERATIONS}

Table 2 lists the common types of sarcoma encountered. Although most frequently described in the extremities, these tumors are found in the retroperitonium where management may also involve extensive resection. ${ }^{7}$ Overall survival and local recurrence are related to size, grade, and, very importantly, the ability to achieve microscopically clear margins. ${ }^{8-11}$ In comparison with patients with carcinoma, these patients are often younger and in generally good health. It is not uncommon for the tumors to be quite large (Fig. 1) with symptoms principally related to mass effect. For these reasons many centers have recommended an extensive surgical approach to these tumors (Fig. 2). 
Table 2 Common Types of Sarcoma

Osteosarcoma

Liposarcoma

Malignant fibrous histiocytoma

Synovial cell sarcoma

Fibrosarcoma

Leiomyosarcoma

Ewing sarcoma

A

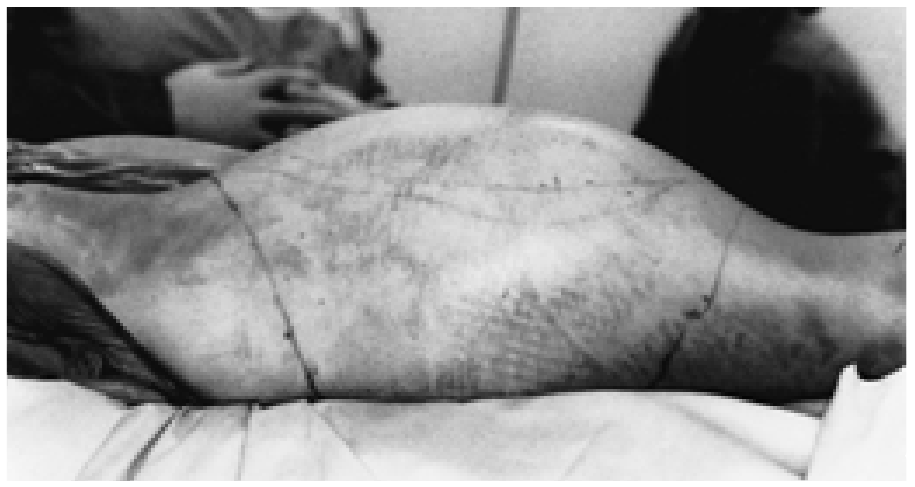

B

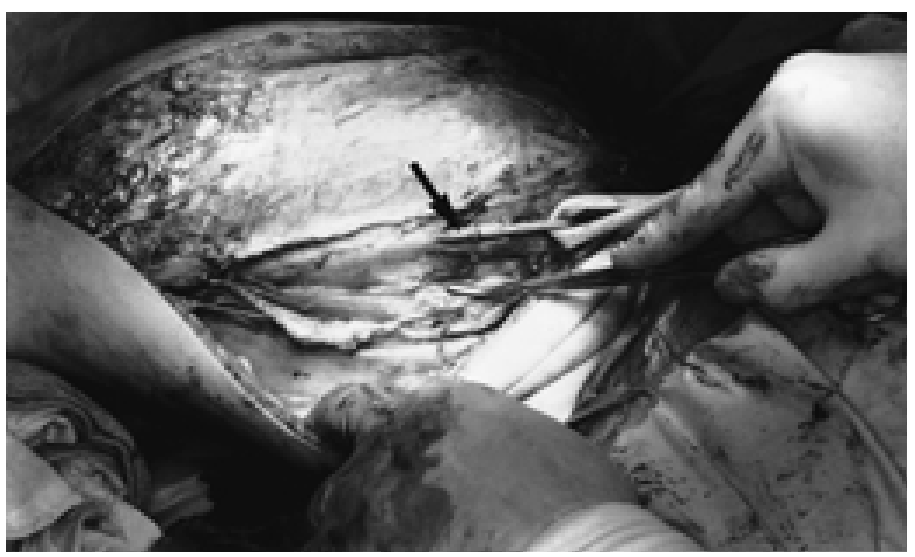

Fig. 1 Preoperative (A) and intraoperative (B) photos of a massive leiomyosarcoma of the thigh. The tumor was adjacent to but not invading the superficial femoral artery (arrow). 


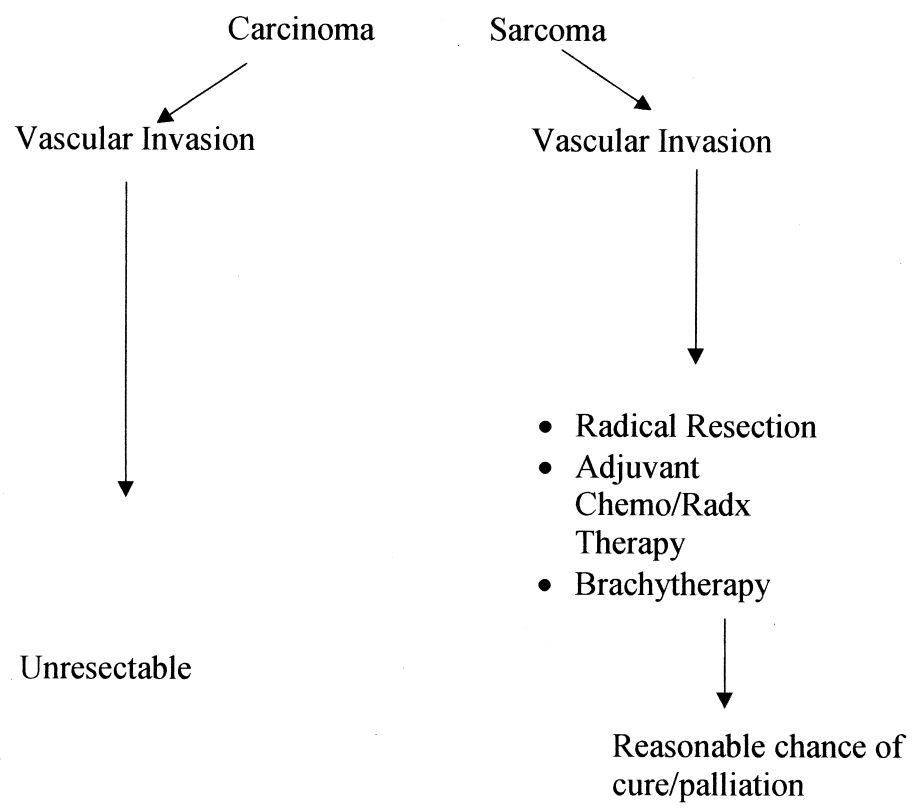

Fig. 2 Management of sarcoma.

\section{EXTERNAL BEAM RADIATION AND BRACHYTHERAPY}

A requirement for a successful limb-sparing procedure is the ability to render the patient free of all, including microscopic, disease. This has traditionally been accomplished with external beam radiation usually in doses ranging from 3000 to 7000 rad. Disadvantages of external beam radiation include deleterious effects on wound healing if administered within 2 to 3 weeks postoperatively and local effects on soft tissues, blood vessels, and vascular grafts. ${ }^{12,13}$ These problems have largely been circumvented by the use of brachytherapy. Fine catheters are placed in the immediate area of the tumor upon completion of the surgical dissection. Radioactive beads are then loaded in the immediate postoperative period, thus enabling the patient to begin radiation sooner. Because the dose of radiation is concentrated in the area of the tumor, there are no significant effects on wound healing. As can be seen in Figure 3, the risk of prosthetic graft contamination if placed in immediate contact with these catheters is significant; thus a means to separate the two must be planned preoperatively.

\section{PREOPERATIVE PLANNING}

A multidisciplinary approach to these tumors is mandatory for successful outcome. The interdisciplinary strategy should be developed in the preoperative 


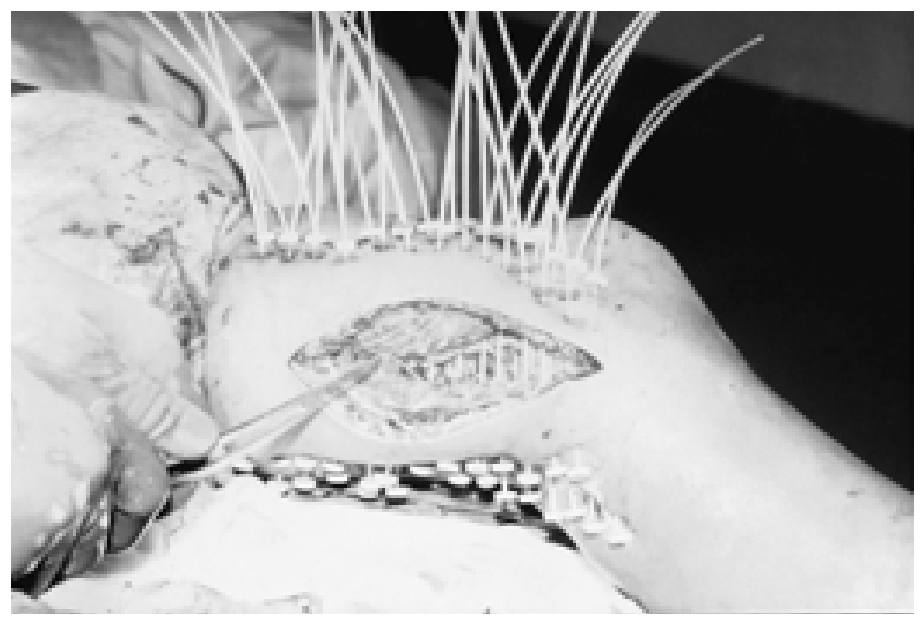

Fig. 3 Brachytherapy catheters placed for postoperative radiation.

rather than intraoperative setting. In cases involving emergent intraoperative vascular consultation and/or procedures, the perioperative morbidity and mortality are extremely high. ${ }^{14}$ In addition to vascular surgery, plastic surgical expertise is required because large defects, many of which involve vascular reconstructions or prosthesic grafts, are created and require coverage. Table 3 lists issues that should be addressed preoperatively. Arterial lines and central lines should not be placed in an extremity that is involved or potentially involved with tumor. Reconstruction of the innominate vein, inferior vena cava (IVC), or proximal common iliac veins may require prosthetic grafts larger (up to $16 \mathrm{~mm}$ ) than routinely stocked in most operating rooms. Although a great deal of attention is paid to the tumor and the arteries and veins involved, it is important that the arterial and venous drainage of potential rotational flaps be protected during the dissection (Table 4). Resection of

Table 3 Preoperative Checklist

Line Placement (A-line, central lines)

Available grafts

Type and sizes (up to $16 \mathrm{~mm}$ )

Preservation of arterial and venous drainage

Potential need for rotational or free flaps

Potential for bowel contamination (bowel prep/staging)

Sequencing of maneuvers to minimize ischemia time

Use of the pneumatic tourniquet

Postoperative drains and brachytherapy catheters 
Table 4 Flaps for Local-Regional Wound Coverage

\begin{tabular}{|c|c|c|c|}
\hline Flap & Type & Vascular Pedicle & Application \\
\hline Latissimus dorsi & $\mathrm{mf}, \mathrm{mcf}$ & Thoracodorsal & $\begin{array}{l}\text { Axilla, ipsilateral chest wall, forequarter, } \\
\text { lumbar }\end{array}$ \\
\hline Pectoralis major & $\mathrm{mf}, \mathrm{mcf}$ & Thoracoacromial & Neck, sternum, mandible \\
\hline Scapular & Skin & Subscapsular & Axilla, chest, shoulder \\
\hline Rectus abdominus & $\mathrm{mf}, \mathrm{mcf}$ & $\begin{array}{l}\text { Superior or } \\
\text { inferior epigatric }\end{array}$ & $\begin{array}{l}\text { Chest wall, sternum, contralateral } \\
\text { abdomen, hemipelvectomy }\end{array}$ \\
\hline Gracilis & $\mathrm{mf}, \mathrm{mcf}$ & Profunda & Perineum, rectum, vagina, bladder \\
\hline Sartorius & $\mathrm{mf}$ & Profunda & Groin \\
\hline Tensor fascia lata & $\mathrm{fcf}$ & $\begin{array}{l}\text { Lateral femoral } \\
\text { circumflex }\end{array}$ & Groin, lower abdomen \\
\hline Gastrocnemius & $\mathrm{mf}, \mathrm{mcf}$ & $\begin{array}{l}\text { Medial or lateral } \\
\text { geniculate }\end{array}$ & Distal femur, knee, proximal tibia \\
\hline
\end{tabular}

mf: muscle flap, mcf: musculocutateous flap, fcf: fasciocutaneous flap.

intraabdominal and retroperitoneal sarcomas may require concomitant bowel resection and prosthetic vascular reconstruction. In this setting a preoperative bowel prep (mechanical and antibiotic) is required. In addition, plans to correctly sequence operative maneuvers so that risk of prosthetic graft contamination is minimized must be coordinated and planned. Examples would include extraanatomic (fem-fem) bypass with coverage of the graft or anatomic vascular reconstruction with greater omental coverage prior to performing bowel resection. Staging that minimizes ischemia time is also important. A pneumatic tourniquet may be useful for tumors in the extremity and is commonly used by orthopedic oncologists. Of note, the dissection plane between a tumor and an artery is much more apparent when the artery is pulsatile. The tourniquet should therefore be let down during this part of the procedure. Finally, a means should be devised to separate brachytherapy catheters (Fig. 3) from fresh prosthetic grafts because these catheters are in direct continuity with the external environment.

\section{PREOPERATIVE IMAGING}

Standard preoperative imaging includes computed tomography (CT) scanning and very frequently magnetic resonance imaging (MRI). These modalities establish the size of the tumor and general extent of involvement. Major invasion or encapsulation of vascular structures is readily apparent. However, these studies lack specificity for determining subtle vascular invasion by adjacent tumors that may necessitate vascular resection. In these cases the final determination must be made intraoperatively. We have found arteriograms to be of no value in determining presence or absence of tumor invasion, with 
most studies appearing entirely normal or showing nonspecific displacement. In general, arteriograms should be reserved for patients with abnormal pulses distal to the tumor as a means of planning the appropriate bypass procedure.

Of greater significance is the preoperative assessment of venous involvement and, more importantly, venous patency. Even limited involvement of major veins by these tumors can lead to thrombosis, many of which are chronic. Here venous reconstruction is unnecessary, and efforts should emphasize preservation of established collateral from the involved extremity. An example would be the use of a midline laparotomy incision and avoiding lateral extensions that may require ligation of the inferior epigastric veins and other superficial collateral along the lower lateral abdominal wall. Such maneuvers may reduce the incidence of postoperative edema in the extremity ipsilateral to a retroperitoneal sarcoma.

Duplex scanning is usually sufficient in the extremity, although it may be less reliable in the abdomen, pelvis, thoracic outlet, and chest. Magnetic resonance venography (MRV) in association with duplex ultrasound ${ }^{15}$ or contrast venography ${ }^{16,17}$ has been shown to have a sensitivity ranging from 97 to $100 \%$ and a specificity of $95 \%$. The specificity improves in the thigh and calf. A preliminary study ${ }^{18}$ using gadolinium enhancement has a defined criterion that differentiates acute from chronic thrombus. This may be of use in determining which patients should undergo venous reconstruction versus ligation. Contrast venography, especially if injected close to the area in question, provides highly accurate information with minimal morbidity.

\section{TECHNICAL POINTS}

An algorithm for proceeding with the dissection is shown in Figure 4. Major arteries and veins that are clearly encapsulated by tumors should be resected en block with appropriate reconstruction (Fig. 5). Patients should be heparinized in the standard fashion prior to clamping with total ischemia times kept to less than 1 hour if possible. The more difficult determination is that of actual involvement of a major artery or vein by a tumor that is in close approximation. As previously emphasized, long-term survival and recurrence depend greatly on obtaining clear microscopic margins. Therefore, concerns exist about leaving tumor behind in efforts to avoid major vascular resection. In general, vascular structures are displaced by these tumors rather than directly invaded or encased. In these cases there is a plane, often apparent on preoperative CT or MRI, that allows dissection of the tumor off the associated vascular structure. Frozen sections are not usually done, and it is felt that microscopic disease, if any remains, would be adequately treated with postoperative radiation. However, if questions exist regarding the adequacy of the margin, en block resection and reconstruction should be performed. In no case should gross tumor be left behind. On occasion, an arterial or venous tributary directly feeding or draining the tumor may enter the respective 


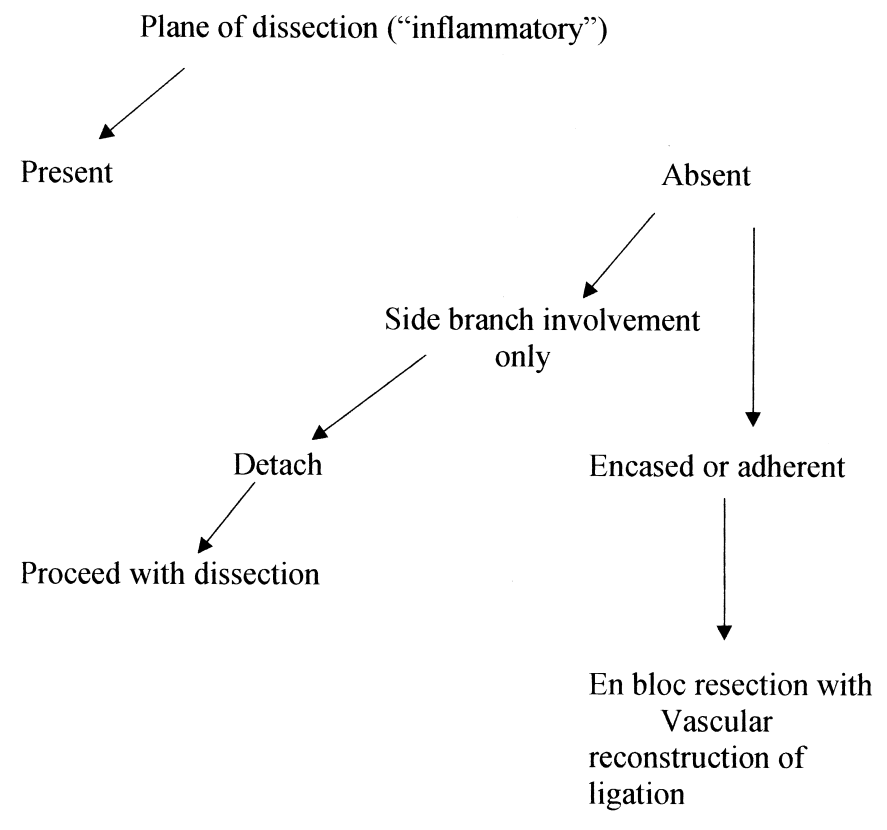

Fig. 4 Algorithm for resection of sarcoma/involved vascular structures.

major artery or vein such that an otherwise clear plane is lost, giving the impression of direct involvement at that point. Often detachment of these tributaries flush with the major vessel reestablishes the plane (Fig. 6).

In comparison with Wilms tumor and hypernephroma, in which extraction of tumor thrombus is an established procedure, the appropriate management

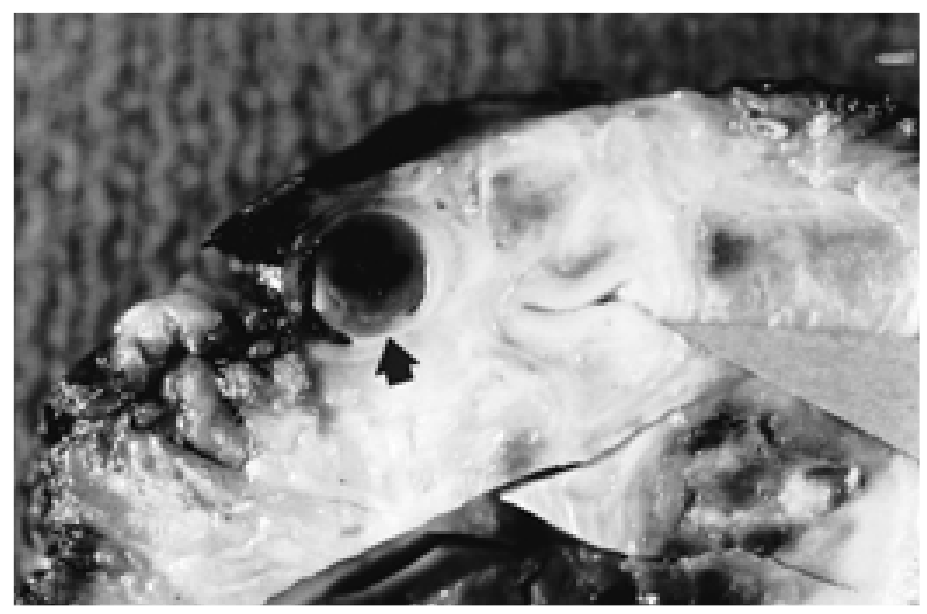

Fig. 5 Resected specimen from patient with a recurrent nonseminomatous germ cell tumor of the left pelvis showing encasement of iliac artery and vein. Both prosthetic iliac arterial and venous bypasses were performed. 


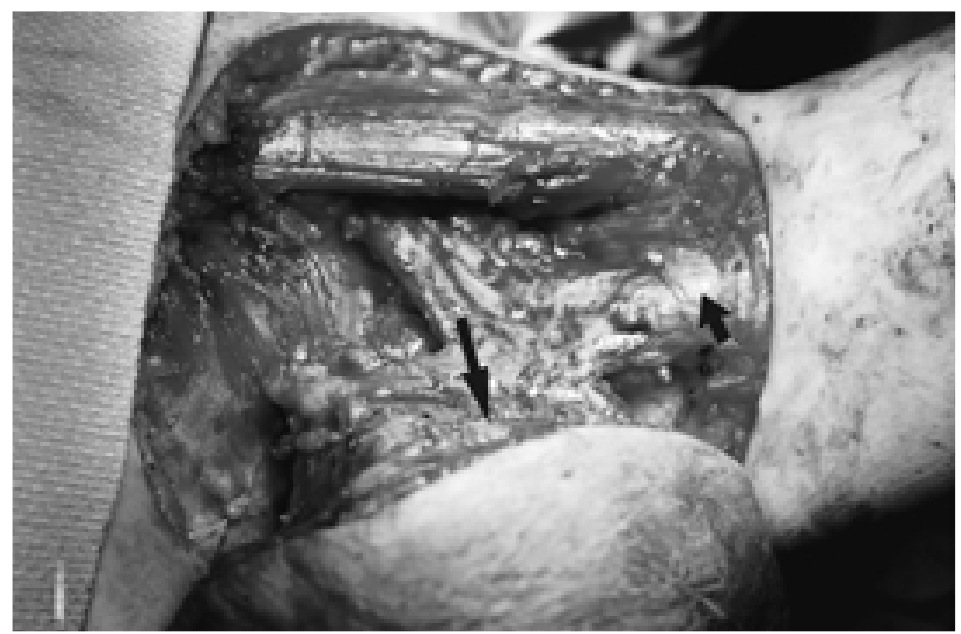

Fig. 6 Intraoperative photo showing close approximation of tumor (long arrow) to axillary artery and vein (short arrow). Detachment of tributary vein reestablished the plane of dissection, and a vascular resection was not necessary.

of tumor thrombus in sarcoma is poorly defined, and it is therefore difficult to make recommendations. If faced with a tumor thrombus, our approach would be resection of the involved vein followed by the vascular reconstruction as indicated.

\section{ARTERIAL RECONSTRUCTION}

The extent of tumor involvement dictates the extent of arterial resection. Most commonly interposition grafting will be needed, although primary endto-end anastomosis or patch angioplasty if feasible would be preferred. If possible, autogenous vein should be used for arterial reconstructions in the extremities because the incidence of wound complications (lymph leak, skin edge necrosis, infection) is higher. The proximal greater saphenous vein is usually large enough to use for any reconstruction below the inguinal ligament and in some cases the external iliac artery. For reconstructions involving the aorta, common iliac artery, and subclavian arteries prosthetic grafts will be necessary. Dacron and PTFE may be used interchangeably. If it is necessary to reconstruct the proximal superficial femoral artery it is helpful to leave a small cuff of proximal superficial femoral artery that can then be oversewn in the event that graft removal becomes necessary. This approach maintains in-line flow to the profunda collateral network and may sustain limb viability. Perioperative intravenous heparin should be used to prevent distal thrombosis while collateral becomes established.

Tumors in the neck may require resection of the common carotid artery. When this is done in association with a major resection, large defects are 
created that may be associated with significant wound complications. Such complications in association with a vein or prosthetic bypass subject the patient to the risk of carotid "blowout" and its attendant morbidity. Myocutaneous flaps will reduce but not eliminate these complications. For this reason, in patients with large soft tissue defects, redo operations, and patients requiring postoperative radiation, we prefer common carotid ligation if at all possible. This can be safely performed in patients with no evidence of extracranial occlusive disease and either stump pressures or preoperative balloon occlusion pressures of 60 or greater. Collateral flow retrograde through the external carotid artery maintains patency of the internal carotid. Should internal carotid ligation be necessary, the patients should be well anticoagulated prior to ligation and in the perioperative period to prevent rapid propagation or embolization of thrombus from the blind stump of the internal carotid into the middle and anterior cerebral circulations. In patients who will not tolerate carotid ligation, an extra anatomic vein bypass from the ipsilateral subclavian artery or the contralateral carotid may remain isolated from wound complications in the area of major dissection.

\section{VENOUS RECONSTRUCTION}

Although controversial it is our practice to reconstruct all major veins that are patent (Table 5). In so doing, edema and related disability in an involved extremity is minimized. In patients with extensive extremity dissections, lymphatic disruption, dead space, and large skin incisions, edema increases the chance of wound infection and related complications. In addition, external beam radiation, which may be necessary in the postoperative period, is contraindicated if there are open wounds or other complications. Therefore, venous reconstruction may benefit these patients until the incisions are healed if not for the long term. In general, we would not reconstruct the

Table 5 Recommendations for Venous Reconstruction

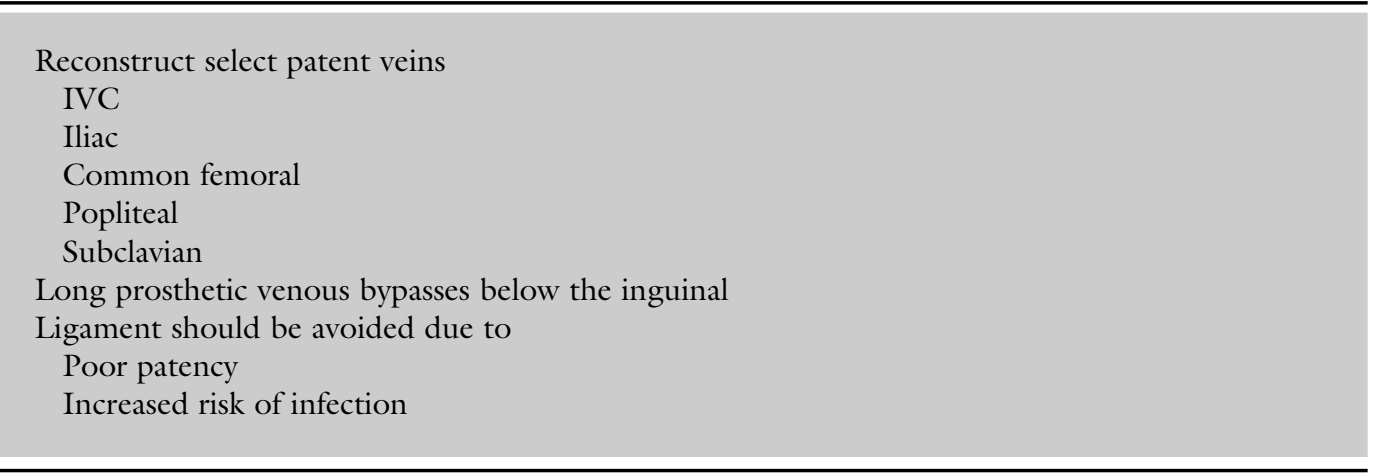


superficial femoral vein, especially long segments, because patency rates are low, the rate of infection of a thrombosed new graft is high, and morbidity is minimal if the profunda venous system is intact. ${ }^{19,20}$ For similar reasons we would not reconstruct the axillary vein, although it may be argued that such may be beneficial in the setting of concomitant disruption of lymphatic drainage. The effects of popliteal vein ligation have been extensively reviewed in the trauma literature and suggest that reconstruction should be performed to minimize outflow resistance and enhance the patency of arterial reconstruction even if intermediate patency is limited..$^{21}$ The long-term natural history of popliteal vein ligation versus reconstruction has never been studied in a randomized prospective fashion, and therefore true differences in regard to postphlebitic sequelae are unknown. However, most authors agree that popliteal vein injuries should be repaired if feasible. ${ }^{22-24}$ In addition, as noted above, these extremities have extensive incisions and massive dead space with the potential for lymphatic leakage, wound edge necrosis and separation, and infection. For this reason popliteal vein reconstruction, which minimizes edema even if only until the incisions are healed, may be beneficial. We would use a proximal segment of the contralateral greater saphenous vein unless the procedure requires resection of the ipsilateral greater saphenous vein. Postoperatively patency is enhanced by the use of pneumatic compression stockings, if tolerated by the patient, and low-dose intravenous heparin followed by anticoagulation with coumadin, as long as the reconstruction remains patent.

For major venous reconstructions in this setting primary end-to-end anastomosis is rarely possible. Often a portion of the vein wall maybe resected and closure performed with an autogenous patch. Larger intraabdominal segments should be replaced with an interposition graft. For these reconstructions PTFE is becoming the conduit of choice ${ }^{25-27}$ because the size mismatch of even proximal greater saphenous vein is significant and the patency of a spiral autogenous segment, which is cumbersome to create, offers no advantage in terms of patency. ${ }^{26}$ Arteriovenous fistulas to enhance patency may be beneficial for reconstructions involving the common femoral and iliac veins but are probably of limited benefit in reconstruction of the superior or inferior vena cava.

An 8- to 10-mm segment of PTFE is ideal for replacement of the common femoral vein, the main disadvantage being the risk of infection if wound complications occur. Should this occur the prosthetic material should be removed and the vein ligated.

It is particularly important to perform surveillance of venous reconstructions as intervention with balloon angioplasty and stent placement can enhance secondary patency. Duplex surveillance is generally adequate, although specific criteria for estimating degree of stenosis do not exist. For more centrally located reconstructions MRA/MRV may be useful. If questions still exist a contrast study will be necessary. 


\section{CLOSURE OF SOFT TISSUE DEFECTS}

When primary closure is not feasible, consultation with plastic surgery to provide single-stage vascularized wound coverage is indicated. Successful primary coverage promotes healing, reduces hospital stay, and enables the wound to better tolerate subsequent treatments such as brachytherapy or external beam radiation. Preoperative review of the anticipated resection with preservation of structures necessary for reconstructive closure is key to a successful collaboration. This includes incision planning, identification of vascular pedicles for flaps, and conservation of muscle, fascia, or skin adjacent to or contiguous with the resection defect (Fig. 7).
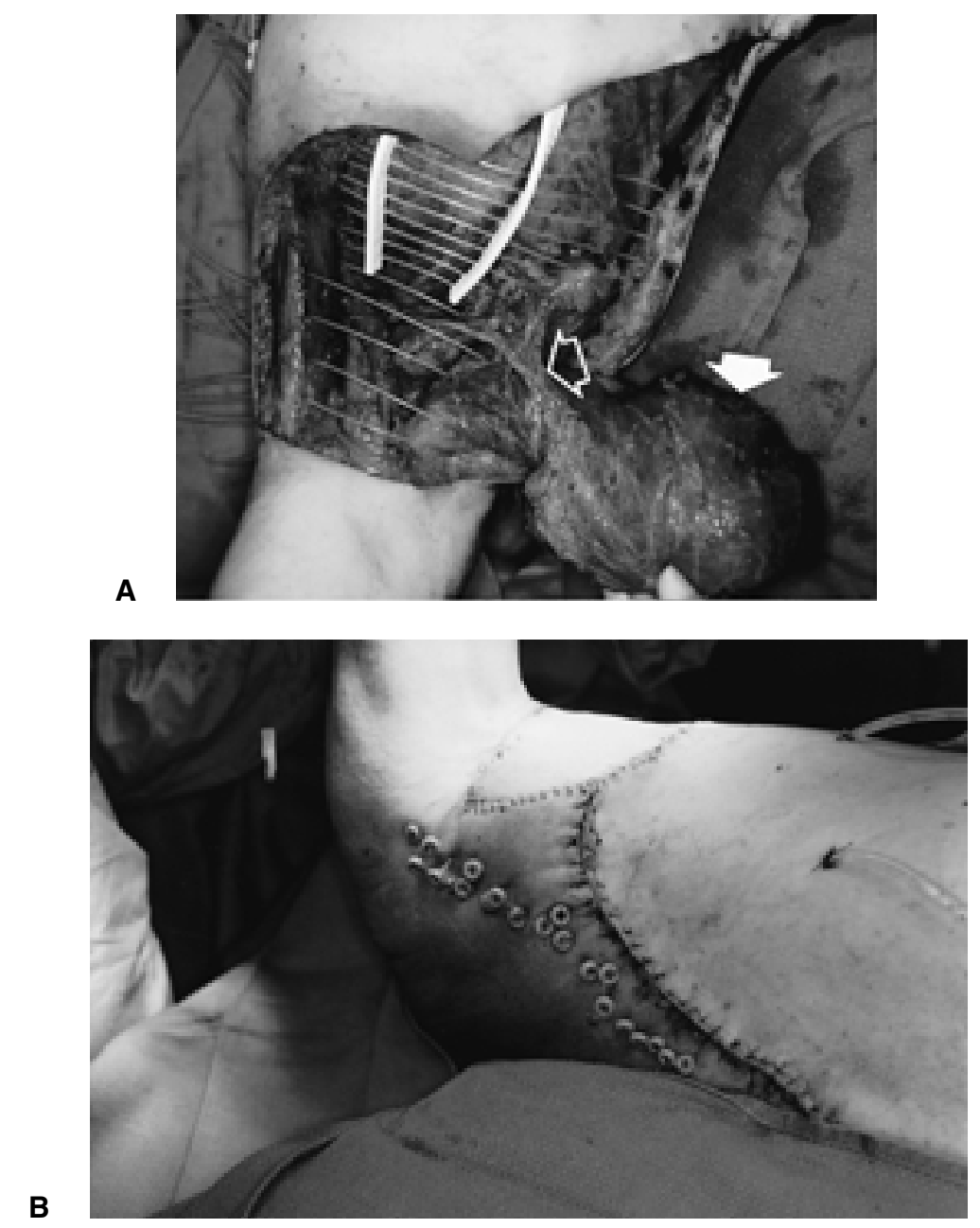

Fig. 7 (A) A large soft tissue defect after resection of a malignant schwannoma of the left axilla and placement of brachytherapy catheters. Coverage was achieved with a latissimus dorsi myocutaneous flap (solid arrow). Rotated on its vascular pedicle, the thoracodorsal artery and vein (open arrow). (B) The completed closure. 
Although microvascular transplantation of distant or free flaps is an option, the zone of sarcoma resection is often a compromised free-flap recipient site. The quality of recipient vessels and anastomotic patency are adversely affected by prior radiation damage to local vasculature and by the procoagulant property of vessels near the tumor margin secondary to inflammatory or desmoplastic reaction. This is true in many cases of primary resection but is invariably the case for recurrent sarcoma requiring salvage resection. In addition, prolonged operative time and donor site morbidity are not trivial concerns for patients already compromised by chemotherapy-induced immunosuppression or tumor inanition. The selection of free-flap coverage is most appropriate when no other options are feasible but should not preclude simpler, equally expedient alternatives and should never supplant preoperative consultation.

When possible, the choice of local or regional flaps reduces operative time and morbidity. The latissmus dorsi, pectoralis major, rectus abdominus, sartorius, gracilis, and gastrocnemuis muscles with or without composite skin flap attached are the workhorses for coverage of major soft tissue defects of the trunk and limbs (Table 4). Axial flaps such as the tensor fascia lata and scapular flap or skin flaps based on intercostal perforators are useful, depending on the location and nature of the defect. Muscle flaps are preferred where vascularized bulk is needed to obliterate dead space, improve lymphatic drainage, and restore normal contour. Any vascularized flap can be placed directly over Marlex to achieve closure of a full-thickness defect of the chest wall or abdomen. This also applies to the direct coverage of exposed vascular prostheses and orthopedic appliances.

\section{ANTICOAGULATION}

Veins in the field of resection are often thick-walled, inflamed, and likely have a procoagulant-type activity. By definition, these patients with cancer are hypercoagulable and subject to venous thrombosis. For this reason, even in the absence of venous reconstruction we maintain patients on low-dose intravenous heparin in the perioperative period. If there is marked perivenous inflammation or a long venous dissection, patients are placed on coumadin for 6 to 12 weeks. In general, we would anticoagulate patients with prosthetic veins bypasses, excluding isolated short segment replacement of the inferior vena cava, for as long as the bypass was patent.

\section{CONCLUSION}

Advances in anesthesia, chemo- and radiation therapy, and surgical strategy have enabled the treatment of large sarcomas involving major vascular structures that were previously unresectable. A multidisciplinary approach with strategic preoperative planning is necessary for a successful outcome. 


\section{REFERENCES}

1. Lawrence W Jr. Concepts in limb-sparing treatment of adult soft tissue sarcomas. Semin Surg Oncol 1988;4:73

2. Willard WC, Hajdu SI, Casper ES, et al. Comparison of amputation with limb-sparing operations for adult soft tissue sarcoma of the extremity. Ann Surg 1992;215:260-275

3. Potter DA, Kinsella T, Glatstein E, et al. High-grade soft tissue sarcomas of the extremities. Cancer 1986:58:190-205

4. Koperna T, Teleky B, Vogel S. Vascular reconstruction for limb salvage in sarcoma of the extremity. Arch Surg 1996:131:1103-1107

5. Karakousis CP, Karmpaliotis C, Driscoll DL. Major vessel resection during limb-preserving surgery for soft tissue sarcomas. Work J Surg 1996:20:345-350

6. Namtisan RN, Karakousis CP. Vascular reconstruction for limp salvage in soft tissue sarcomas. Surgery 1987:101:668-677

7. Jacques DP, Coit DG, Hajdu SI, et al. Management of primary and recurrent soft tissue sarcoma of the retroperitoneum. Ann Surg 1990:212:51-59

8. Lewis JJ, Leung D, Casper ES, et al. Multifactorial analysis of long-term follow-up (more than 5 years) of primary extremity sarcoma. Arch Surg 1999:134:190-194

9. Rosenberg SA, Tepper J, Gatstein E, et al. The treatment of soft tissue sarcomas of the extremities prospective randomized evaluations of 1 ) limb-sparing surgery plus radiation therapy compared with amputation and 2) the role of adjuvant chemotherapy. Ann Surg 1982:196:305-315

10. Brennan MF, Shiu MH. Presentation, demographics and prognostic factors of soft tissue sarcomas, in Shui MH, Brennan MF, eds. Surgical Management of Soft Tissue Sarcoma. Philadelphia, PA: Lea \& Febiger; 1989:45-57

11. Collin C, Hajdu SI, Godbold J, et al. Localized, operable soft tissue sarcoma of the lower extremity. Arch Surg 1986:121:1425-1433

12. Butler MJ, Lane RHS, Webster JH. Irradiation injury to large arteries. Br J Surg 1980:67:341-343

13. Heff H. Sanders EM. Coronary artery occlusion after radiation. N Engl J Med 1972: 286:780-785

14. Bianchi C, Ballard JL, Bergan JJ, et al. Vascular reconstruction and major resection for malignancy. Abstract presented at 70th Annual Meeting Pacific Coast Surgical Association, Los Cabos San Jose del Cabo, Baja, CA: Feb 12-16; 1999

15. Carpenter JP, Holland GA, Baum RA, et al. Magnetic resonance venography for the detection of deep venous thrombosis: Comparison with contrast venography and duplex doppler ultrasonography. J Vasc Surg 1993:18:734-741

16. Evans AJ, Sostman HD, Knelson $\mathrm{MH}$, et al. Detection of deep venous thrombosis: Prospective comparison of MR imaging with contrast venography. AJR 1993:161:131-139

17. Spritzer CE, Norconk JJ Jr, Sostman HD, et al. Detection of deep venous thrombosis by magnetic resonance imaging. Chest 1993:104:54-60

18. Froehlich JB, Prince MR, Greenfield LJ, et al. "Bull's-eye" sign on gadolinium-enhanced magnetic resonance venography determines thrombus presence and age: A preliminary study. J Vasc Surg 1997:26:809-816

19. Brown PM Jr, Kim VB, Lalikos JF, et al. Autologous superficial femoral vein for aortic reconstruction in infected fields. Ann Vasc Surg 1999:13:32-36

20. Claggett GP, Valentine JR, Hagino RT. Autogenous aortoiliac/femoral reconstruction from superficial femoropopliteal veins: Feasibility and durability. J Vasc Surg 1997:25: 255-270

21. Hobson RW, Wright CB, Swan KG, et al. Current status of venous injury and reconstruction in the lower extremities. In Bergan JJ, Yag JST, eds. Venous Problems. Chicago: Year Book; 1978:469 
22. Pasch AR, Bishara RA, Schuler JJ, et al. Results of venous reconstruction after civilian vascular trauma. Arch Surg 1986:121:607-611

23. Parsch AR, Bishara RA, Lim LT, et al. Optimal limb salvage in penetrating civilian vascular trauma. J Vasc Surg 1986;23:189-195

24. Rich NM, Hobson RW, Collins GJ Jr, et al. The effect of acute popliteal venous interruption. Ann Surg 1976:183:365-368

25. Bower TC, Nagorney DM, Cherry KJ, et al. Replacement of the inferior vena cava for malignancy: An update. Abstract presented at the Society for Vascular Surgery, 53rd Annual Meeting. Washington, DC: June 6-7; 1999

26. Gloviczki P, Pairolero PC, Cherry KJ, et al. Reconstruction of the vena cava and its primary tributaries: A preliminary report. J Vasc Surg 1990;II:373-381

27. Sarkar R, Eilber FR, Gelabert HA, et al. Prosthetic replacement of the inferior vena cava for malignancy. J Vasc Surg 1998;28:75-83 
